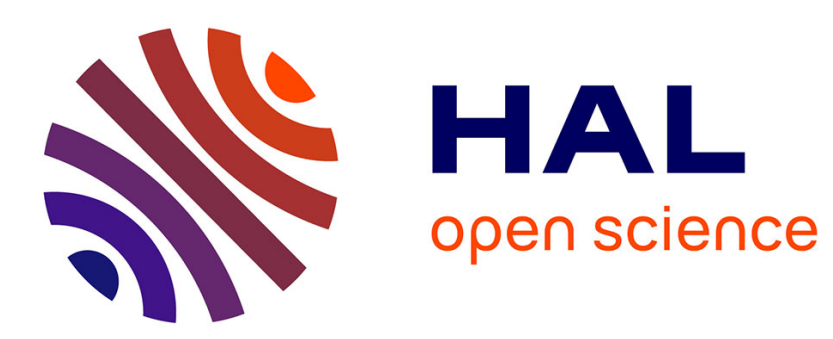

\title{
Robust stability analysis of brake squeal based on a parametric finite element model
}

\author{
Guillaume Fritz, Jean-Marc Duffal, Jean-Jacques Sinou, Louis Jezequel
}

\section{To cite this version:}

Guillaume Fritz, Jean-Marc Duffal, Jean-Jacques Sinou, Louis Jezequel. Robust stability analysis of brake squeal based on a parametric finite element model. SAE Transactions Journal of Passenger Cars: Mechanical Systems, 2007, 116 (6), pp.1829-1837. 10.4271/2007-01-2263 . hal-00324157

\section{HAL Id: hal-00324157 \\ https://hal.science/hal-00324157}

Submitted on 20 Sep 2018

HAL is a multi-disciplinary open access archive for the deposit and dissemination of scientific research documents, whether they are published or not. The documents may come from teaching and research institutions in France or abroad, or from public or private research centers.
L'archive ouverte pluridisciplinaire HAL, est destinée au dépôt et à la diffusion de documents scientifiques de niveau recherche, publiés ou non, émanant des établissements d'enseignement et de recherche français ou étrangers, des laboratoires publics ou privés. 


\title{
Robust Stability Analysis of Brake Squeal Based on a Parametric Finite Element Model
}

\author{
Guillaume Fritz and Jean-Marc Duffal \\ Renault SAS
}

\author{
Jean-Jacques Sinou and Louis Jézéquel \\ Ecole Centrale de Lyon
}

\begin{abstract}
Brake squeal is an instability phenomenon, which is severely dependent on many parameters. This study attempts to assess the effects of their variability on brake squeal behavior through FE computation.

A detailed FE model of a commercial brake corner has been built up in order to predict its nominal squeal behavior. This analysis includes a non-linear preloading step to predict the system working-point and a complex eigenvalue analysis to assess its stability. A parametric study has been conducted in order to estimate the dependency with respect to the friction coefficient.
\end{abstract}

The FE model has been parameterized to investigate the effect of variability. The process includes geometry simplifications to reduce CPU time, allowing far more configurations to be computed. Several parametric studies have been conducted to assess the effects of the friction coefficient, of the rotating direction, of the friction induced damping and of the hydraulic pressure. A numerical matrix test has been undertaken to synthesize the brake behavior in the wide variety of conditions it may encounter. Then, a full factorial design of experiments has been conducted with respect to the friction coefficient and the disc Young Modulus. This analysis shows biparametric coupling patterns and stability charts. Finally, it is possible to rank the parameters with respect to their influence and to assess the performance and the robustness of the system.

\section{INTRODUCTION}

In spite of recent breakthroughs in the mechanical modeling field, brake squeal remains, one of the most common and annoying noise in a car. The key issue deals with the fugitive nature of brake squeal. The challenging point is to be able to predict this high sensitivity to parameters and then to design most robust systems. For a given braking system, the influential parameters are wear and environment parameters, such as hydraulic pressure or temperature. Squeal is also deeply altered by part-to-part variability, which involves uncertain parameters. The last kind of influential parameters includes the parameters chosen during the design process.

In recent years, several techniques dealing with brake squeal prediction has been proposed. The most used one consists in computing the complex eigenvalues of the system in order to assess its stability. Liles has been the first researcher to introduce this kind of analysis on a finite element model [1]. Then, this technique has been progressively improved. The main breakthrough consists in computing the static position of the braking system considering the contacts between parts before extracting the complex eigenvalues. This kind of analysis, which has been fully implemented in ABAQUS V6.4 and later, has been illustrated in several case studies by Bajer et al. $[2,3,4]$. Then, Abu Bakar et al. have studied the effect of brake pad surface topography and have concluded that this point was responsible for the fugitive nature of brake squeal

In this study, the aforementioned analysis has been used to predict the squeal behavior of a commercial braking system in "nominal" conditions. Since this phenomenon is a friction induced instability, a parametric study has been undertaken with respect to the friction coefficient. Then, a parametric model has been built up in order to conduct comprehensive variability analyses and catch the fugitive nature of brake squeal.

\section{DETAILED MODEL}

MODEL

This study deals with the squeal behavior of a commercial front brake. The whole system, consisting of the knuckle, hub, disc, brake and pads, is displayed Figure 1. All the connections between parts have been 
modeled, especially contacts which have been taken into account through surface interactions.

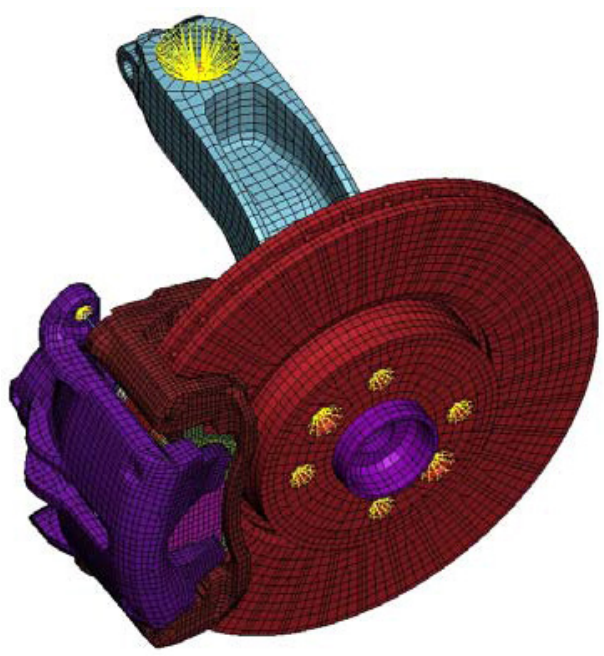

Figure 1: Detailed FE Model

The analysis consists of a non-linear static preloading and an eigenvalue extraction. First, the hydraulic pressure, $\mathrm{P}$, is applied between piston and caliper. Then, a sliding velocity, $v$, and a friction coefficient, $\mu$, are introduced between disc and pads. After these two steps, the equilibrium position corresponding to the steady sliding is obtained. Then, the complex eigenvalues are computed through a projection on the real modal basis method.

\section{NOMINAL ANALYSIS}

The model has been used first to compute the nominal configuration, defined as $\mu=\mu_{0}, v=v_{0}$ and $P=P_{0}$ in forward motion. The static deformed shape highlights the way the pads get in position against the anchor abutments and the way the brake reacts to the braking torque. Since contacts have been modeled as surface interactions, the contact pressures between parts are available and displayed in Figure 2.

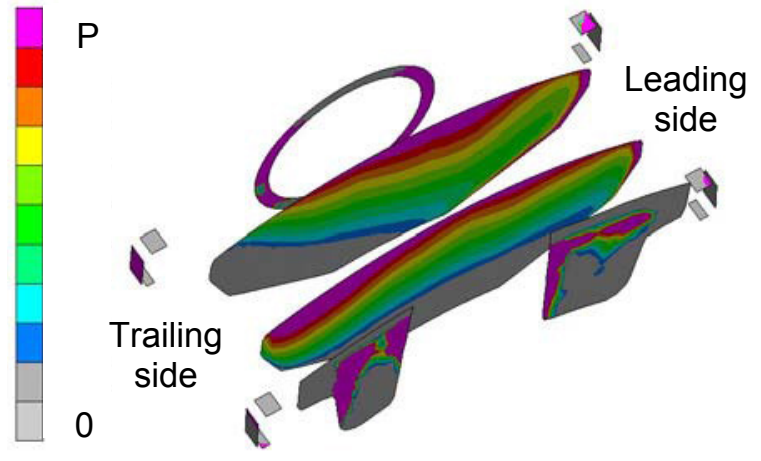

Figure 2: Pressure distribution in nominal conditions

The first point to notice is that parts are not in contact on their whole surfaces (the open contacts are colored in gray). As expected, because of the surface ratios at stake, the maximum pressure is concentrated on the trailing edge abutments that receive the whole friction force. Since the caliper tends to "open", the contact with the outer pad occurs mainly on the upper part of the fingers. The friction force that acts on both sides of the disc tends to skew the anchor and the caliper. Therefore, the center of pressure is shifted towards the trailing edge for the outer pad and towards the leading edge for the inner pad.

The complex eigenvalue analysis detects, on the overall frequency range, six unstable modes. Among them, only one is in the range $1-4 \mathrm{kHz}$ of the so-called low frequency (LF) squeal. In the following, we will focus on this LF squeal. This unstable mode, whose frequency is $1983 \mathrm{~Hz}$, is associated with a complex eigenvector displayed Figure 3 . This mode mainly consists of a twisting mode of the caliper, an opening mode of the anchor and a three nodal line bending mode of the disc featuring traveling waves.

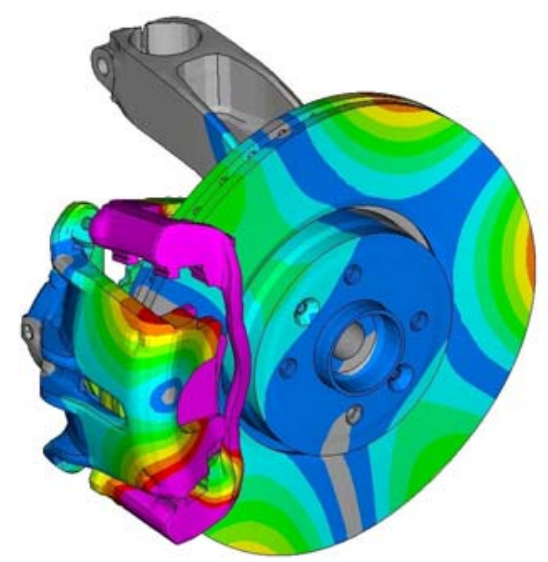

Figure 3: Unstable mode $-1983 \mathrm{~Hz}$

\section{EFFECT OF THE FRICTION COEFFICIENT}

Since friction is the root cause of instabilities, its effect has been investigated through a parametric study with 20 values of the friction coefficient ranging from $\mu_{\min }$ to $\mu_{\max }$. This parameter influences both the static and the dynamic behavior of the brake.

Figure 4 shows the pressure distributions for $\mu_{\min }$ and $\mu_{\max }$. For small values of $\mu$, the distribution is quite homogeneous whereas for large values, the contact occurs on a restricted area. In fact, the more the friction coefficient is, the more important the "skew effect" becomes. Therefore, the center of pressure is gradually shifted towards the trailing edge for the outer pad and towards the leading edge for the inner pad. 


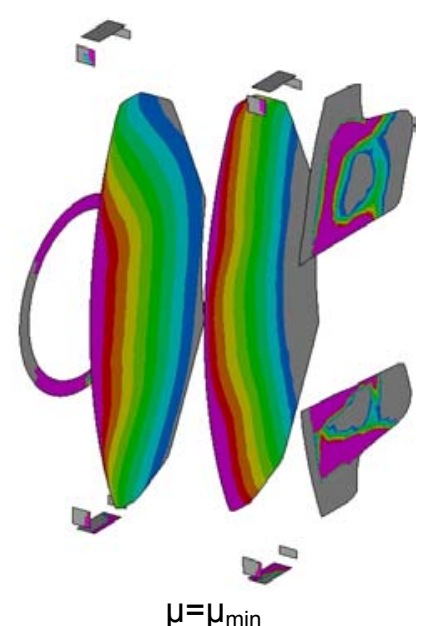

Figure 4: Pressure distribution - friction variability

As far as the dynamic behavior is concerned, the complex eigenvalues are gathered in Figure 5. This figure highlights five unstable modes displayed in red, among which two LF squeals. Note that from now on, the real parts are normalized to 1 , with respect to the value at $\mu_{\max }$ of the $1983 \mathrm{~Hz}$ mode. The pressure and friction coefficient values are normalized with respect to $\mathrm{P}_{0}$ and $\mu_{0}$ respectively.

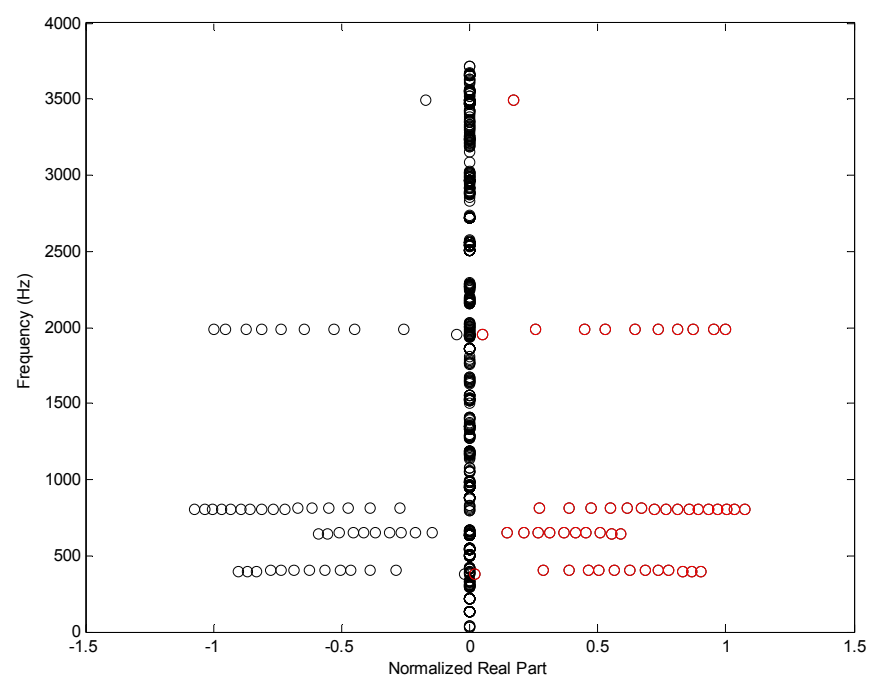

Figure 5: Complex eigenvalues - variability with $\mu$

The evolution of eigenvalues with respect to friction shows the mode coupling aspect of instabilities also referred to as coalescence. This phenomenon has been highlighted first on lumped models and then on linear FE models (cf [7]). Here, the coupling pattern of the $810 \mathrm{~Hz}$ mode, displayed in Figure 6 , looks like linear coalescence curves. Indeed, for $\mu=0$, the system features two real modes apart in the frequency range. As the friction increases, the frequencies of the two modes get closer to each other. At a friction value known as the critical friction value, the two modes reach the same frequency. After that point, also referred to as the bifurcation point, the eigenvalues of the two modes leave the imaginary plane, with opposite real parts. Thus, the mode that features a positive real part is unstable whereas the other one is stable.

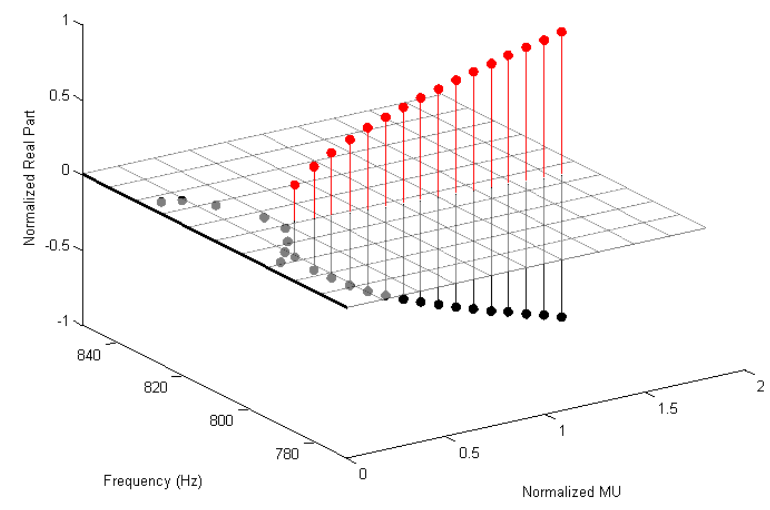

Figure 6: Coalescence curve $-810 \mathrm{~Hz}$

For the $1980 \mathrm{~Hz}$ unstable mode, the phenomena at stake are more complicated as illustrated in Figure 7. Indeed, as explained previously, the static position and the contact pressure distribution depends on the friction value. Here, the change in static solution with $\mu$ alters the dynamic behavior in a significant way. This is the reason why the Figure 7 curves are not smooth, especially for the low values of $\mu$ when the contacts are not yet well established. Here, we follow three modes A, $B$ and C, whose frequencies are initially 1950, 1990 and $2030 \mathrm{~Hz}$ respectively. We can infer from the frequency curve that $B$ seems to be the most sensitive to the static solution. It is worthy to mention that the sudden changes in frequency of mode B correspond to changes in contact conditions between pads and anchor bracket abutments. This accounts for the scattered aspect of this curve. Once the static position stabilized, the curves become smooth again. Hence, a typical mode-coupling pattern appears between the two higher frequency modes.

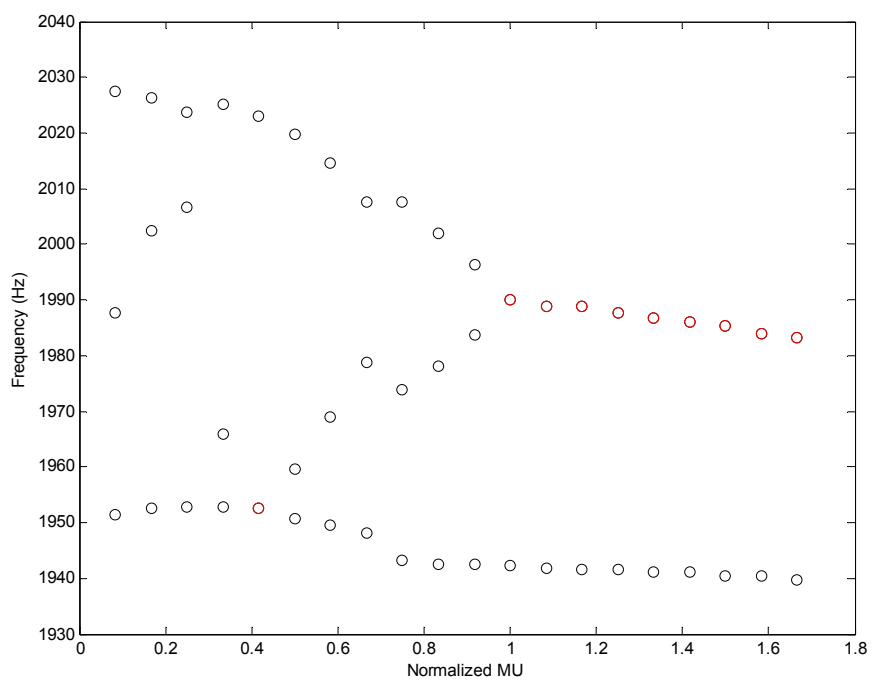

Figure 7: Coalescence curve $-1980 \mathrm{~Hz}$ 


\section{PARAMETRIC MODEL}

\section{MODEL FEATURES}

After the variability to friction, we aim at studying the effect of other influential parameters on the $2 \mathrm{kHz}$ squeal. The detailed model is not well adapted to this task because of its prohibitive CPU cost. Thus, a parametric FE model, displayed Figure 8, has been built up to undertake comprehensive parametric studies. The geometry has been simplified, with respect to the detailed model, but the main dimensions and the material properties have been kept. The detailed model allows us to identify the parts that have insignificant contributions to the system behavior. Thus, the knuckle has been reduced to the mountings on which the anchor bracket is bolted. Moreover, the disc has been modeled as a solid disc with equivalent material properties of the core to consider the cooling fins.

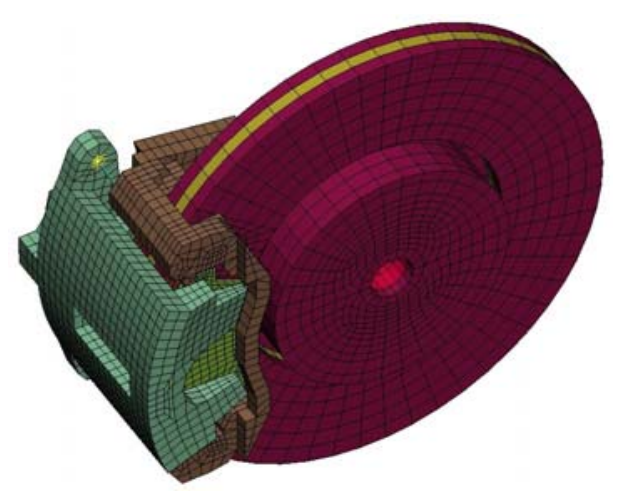

Figure 8: Parametric FE model

The parametric model has been updated to properly reproduce the detailed model behavior in the vicinity of 2 $\mathrm{kHz}$, in terms of frequency, real part and deformed shape. Finally, the model size has been reduced in a significant way: the number of elements has been divided by 4 with respect to the detailed model. Thus, the CPU time cost is drastically reduced, allowing far more configurations to be computed.

\section{NOMINAL FORWARD ANALYSIS}

The analysis of the nominal configuration has been performed first. The static deformed shape is close to the detailed model one, both in terms of position and in terms of contact pressure distribution as we can notice on Figure 9.

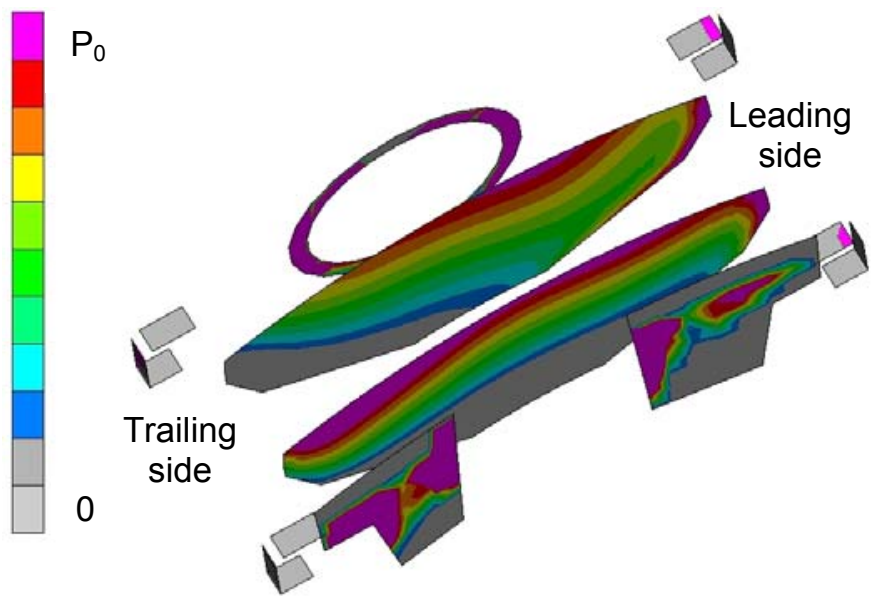

Figure 9: Pressure distribution - forward

About dynamic behavior, the results are consistent with the detailed model ones since a LF squeal is found at $1944 \mathrm{~Hz}$. The deformed shape of this unstable mode, displayed in Figure 10, is quite close to the detailed model one. Indeed, it mainly consists of a twisting mode of the caliper, an opening mode of the anchor and a three nodal line bending mode of the disc featuring traveling waves. Nevertheless, the real part correlation is not as good insofar as they are undervalued by $20 \%$.

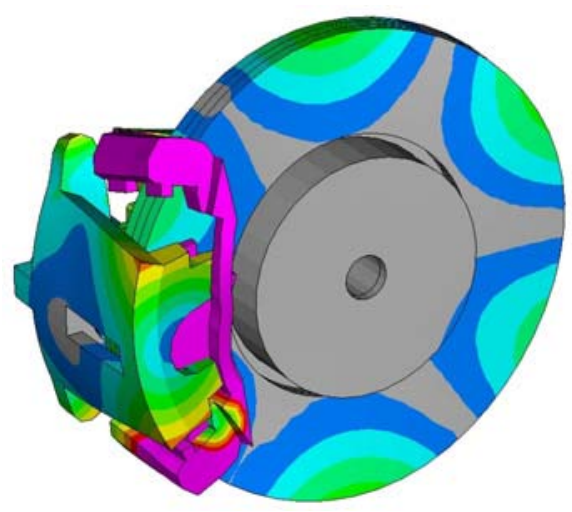

Figure 10: Unstable mode $-1944 \mathrm{~Hz}$

\section{NOMINAL BACKWARD ANALYSIS}

So far, all the analyses have been performed in forward motion. Here, the backward behavior has been computed for $\mu=\mu_{0}$. The pads are in contact with the upper abutments of the anchor bracket. The friction force skew the anchor bracket and the caliper in a reverse way with respect to the forward motion. Nevertheless, the center of pressure is still shifted towards the trailing edge for the outer pad and towards the leading edge for the inner pad as it can be observed in Figure 11. 


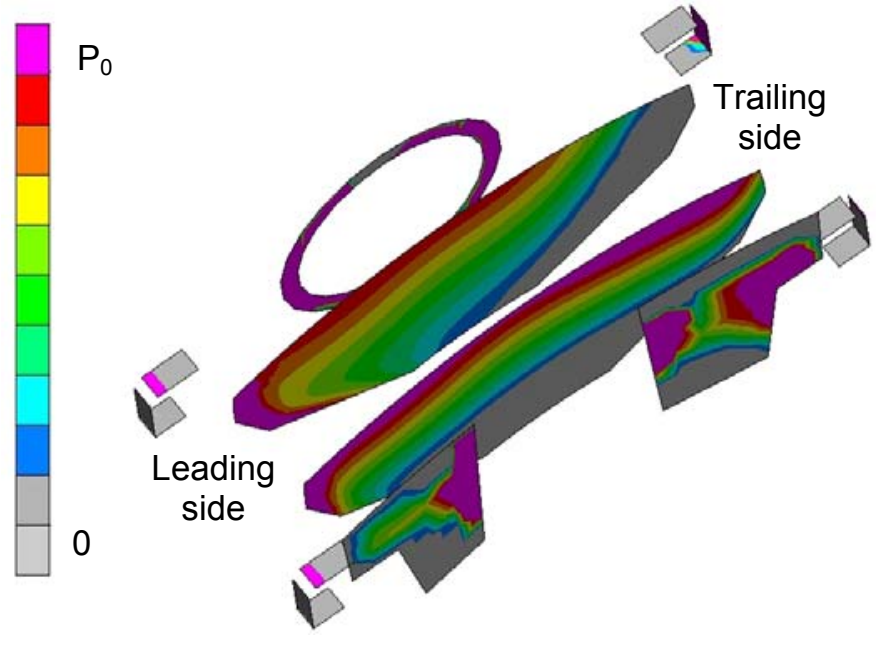

Figure 11: Pressure distribution - backward

\section{EFFECT OF THE FRICTION COEFFICIENT}

Parametric sweep has been refined with a higher resolution on friction coefficient (40 values) to capture the coupling pattern in more detail from 0 to $\mu_{\max }$. Figure 12 , that gathers all the eigenvalues, highlights three unstable modes up to $4 \mathrm{kHz}$. As expected, the correlation is good near the updating frequency but decreases as soon as we get away from it.

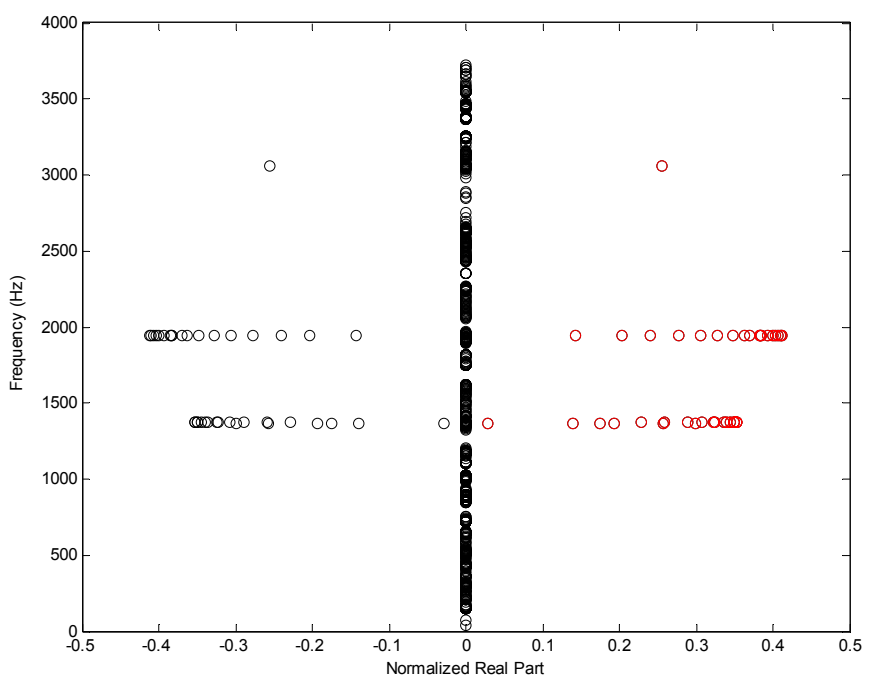

Figure 12: Complex eigenvalues - variability with $\mu$

We will now focus on the phenomena near $1940 \mathrm{~Hz}$. Figure 13 depicts the coalescence pattern on this frequency range in forward motion. This figure follows the evolution of three modes referred to as A, B and C by increasing frequencies and shows broken lines due to changes in static solution. At least three borders marking static position changes can be readily identified. Even if these static nonlinearities occur for different friction coefficient values, the overall variability to friction is well reproduced, with respect to the detailed model. Indeed, $B$ and $C$, whose frictionless frequencies are respectively
1908 and $1964 \mathrm{~Hz}$, coalesce for a normalized friction value, which is close to 1.0 .

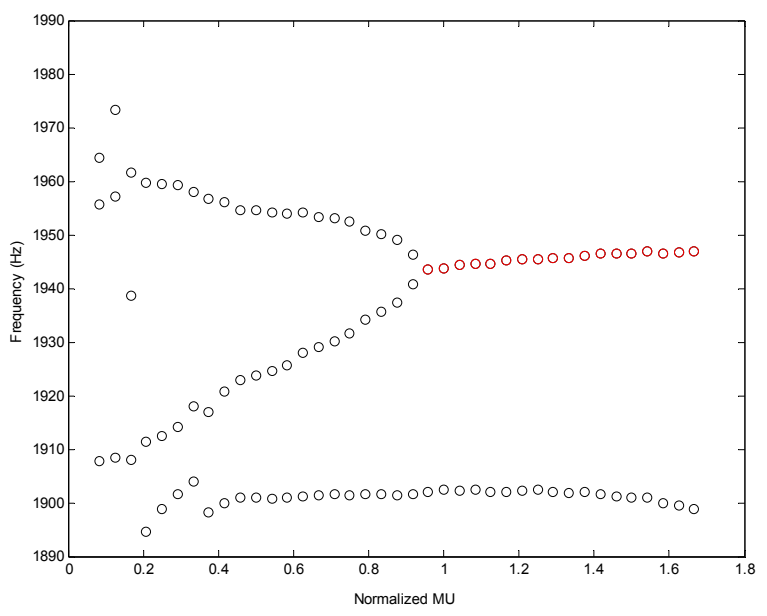

Figure 13: Coalescence curve - forward

The same study has been conducted in backward motion and the results are shown in Figure 14. As the geometry of the brake corner is nearly symmetric, we expect a similar behavior. Indeed, B and C coalesce and lead to an unstable mode at $1935 \mathrm{~Hz}$. Nevertheless, the bifurcation point occurs for a lower friction coefficient value, 0.8 . Moreover the low friction behavior is different, especially since $A$ and $B$ coalesce in the friction range [0.28-0.38].

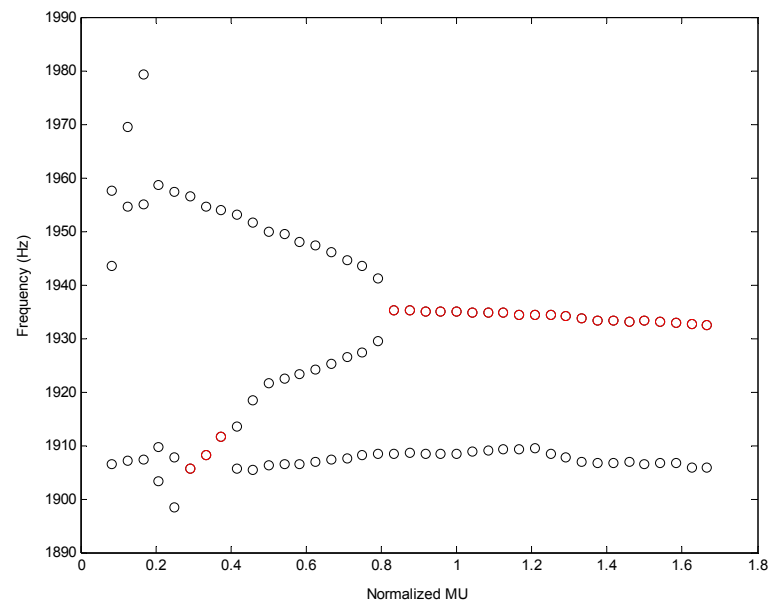

Figure 14: Coalescence curve - backward

If friction induced damping is considered, using the methodology described by Bajer et al. [2,3,4], the forward coalescence curves are altered as illustrated Figure 15. This damping depends on hydraulic pressure and velocity. The values, which have been used here, are respectively $P_{0}$ and $5 \mathrm{~km} / \mathrm{h}$. The main discrepancies appear after the bifurcation point, since the frequencies of the stable and unstable modes are not the same anymore. The friction induced damping tends to shift down the real parts. Moreover, a smoothing effect may be noticed on both frequency and real part curves. 

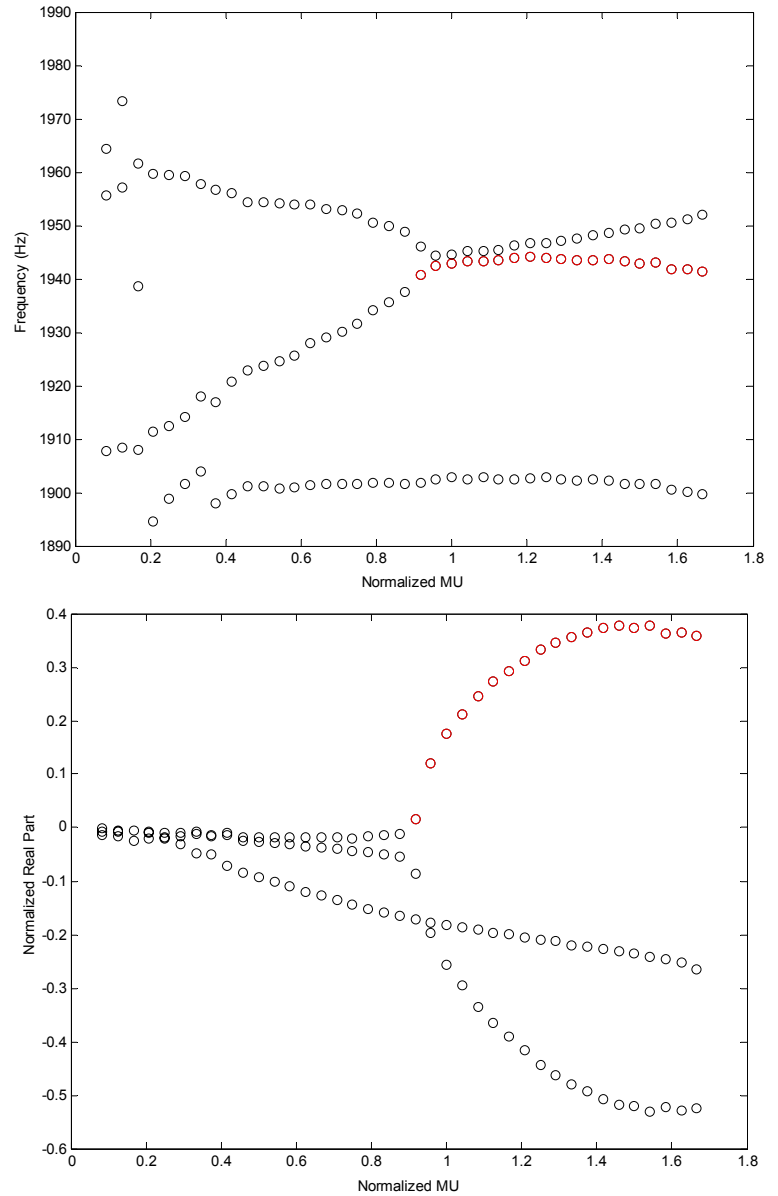

Figure 15: Effect of friction damping on coalescence curves - forward

\section{HYDRAULIC PRESSURE}

The effect of hydraulic pressure has been investigated in forward motion for $\mu=\mu_{0}$ with $\mathrm{P}$ ranging from 0 to $2 \mathrm{P}_{0}$. Figure 16 shows the evolution of eigenfrequencies with respect to this parameter.

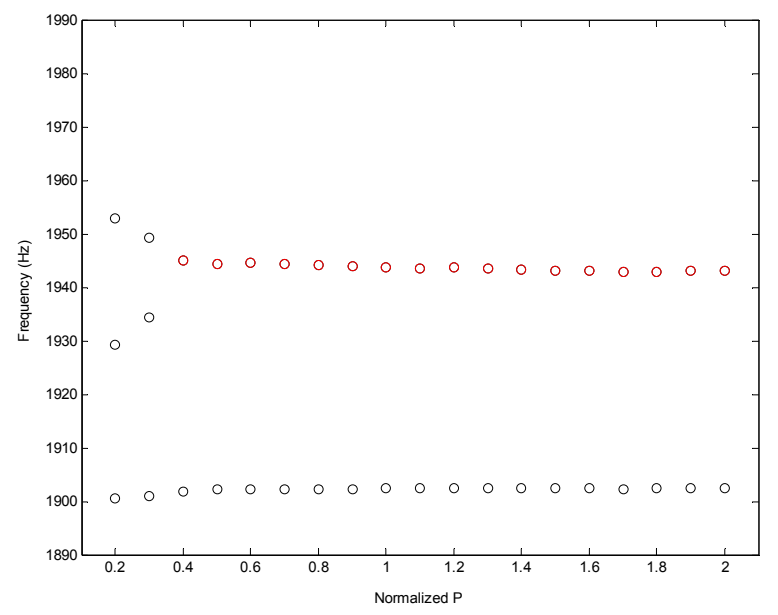

Figure 16: Effect of hydraulic pressure

For small values, the hydraulic pressure is a key parameter dealing with the static position. Indeed, at low pressure, the system is stable and then, a coupling pattern appears at $\mathrm{P}=0.4$ and leads to an unstable mode at $1944 \mathrm{~Hz}$. For $P>0.4$, the static position is well established and the variability of the eigenvalues with pressure is far less important.

\section{NUMERICAL MATRIX TEST}

In the FE model, many parameters may be identified as utilization dependent or environment dependent. Here, four parameters have been chosen, among which the friction coefficient is the most important. They will be referred to as $\mu, \mathrm{Pa}_{1}, \mathrm{~Pa}_{2}$ and $\mathrm{Pa}_{3}$. After having specified a variation range for each parameter, a numerical matrix test has been conducted. Indeed, 360 experiments have been computed in order to assess the brake behavior in a wide variety of configurations. All the predicted unstable modes are displayed in Figure 17.

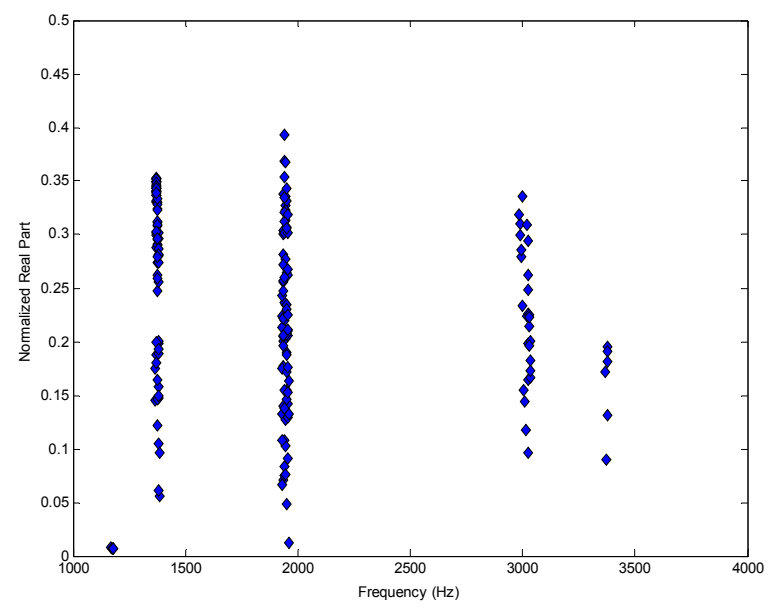

Figure 17: Numerical matrix test

As expected, the aforementioned 1375, 1940 and $3000 \mathrm{~Hz}$ modes are found with scattered features. Furthermore, two other squeals appear at 1170 and $3400 \mathrm{~Hz}$. Nevertheless, the key point is to assess the probability of these squeals, also referred to as the squeal occurrence. As illustrated Figure 18, it has been computed every $100 \mathrm{~Hz}$ over all the experiments. The 2 $\mathrm{kHz}$ squeal turns out to be the most likely to occur and its occurrence reaches $24 \%$. This occurrence may also be analyzed with respect to parameters variations, as illustrated Figure 19. We can notice that the parameters effects on the brake stability are either monotonic, for $\mu$ and $\mathrm{Pa}_{3}$, or non-monotonic, for $\mathrm{Pa}_{2}$. The main advantage of these graphs is to rank the parameters in order of importance. As expected, the friction coefficient is the most important parameter since the occurrence reaches nearly $100 \%$ as it increases. Then, the order of importance is $\mathrm{Pa}_{3}, \mathrm{~Pa}_{2}$ and $\mathrm{Pa}_{1}$. 


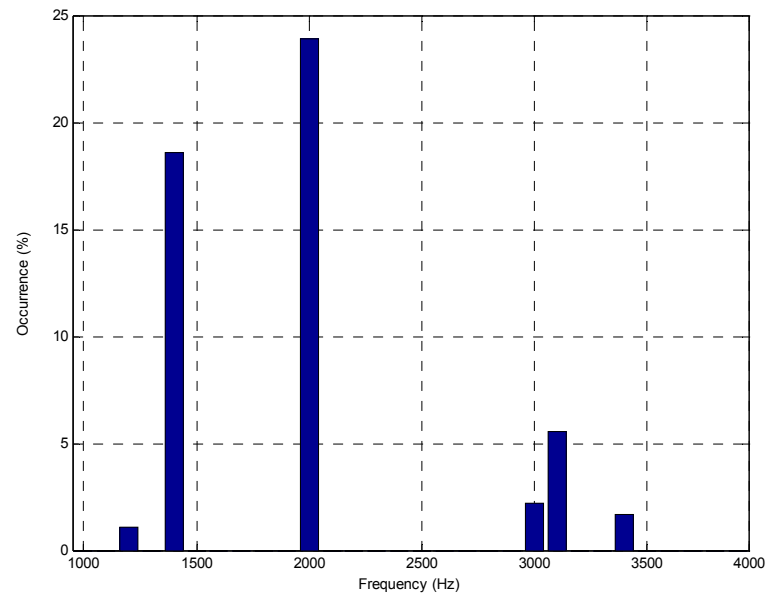

Figure 18: Squeal occurrence

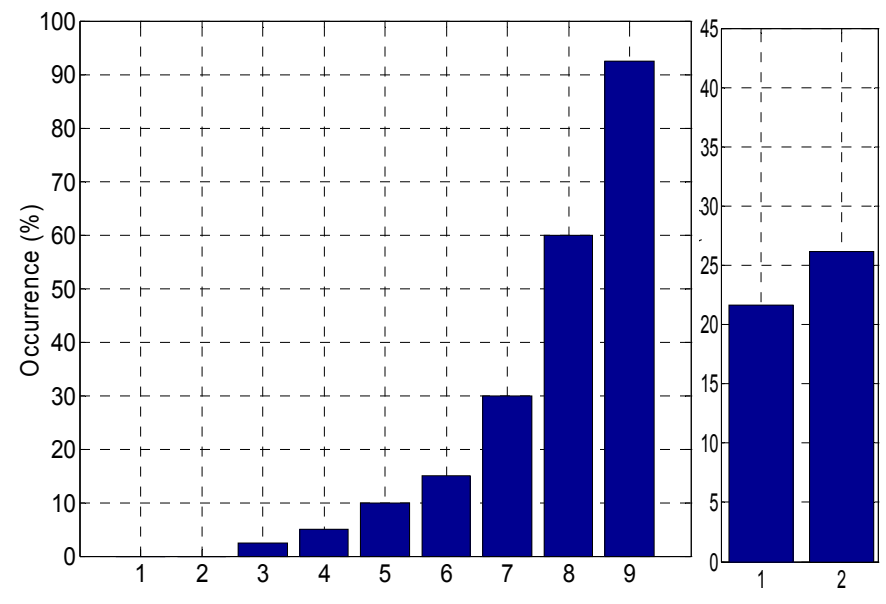

$\mu$

$\mathrm{Pa}_{1}$

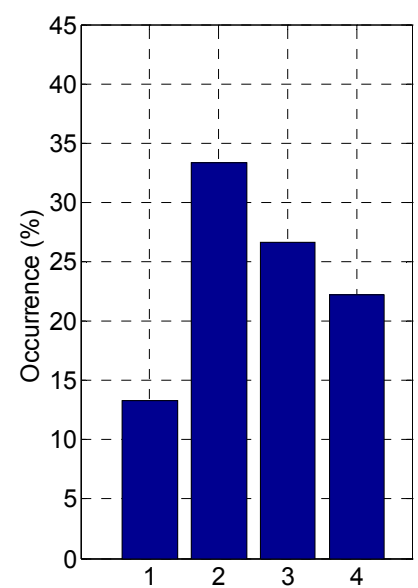

$\mathrm{Pa}_{2}$

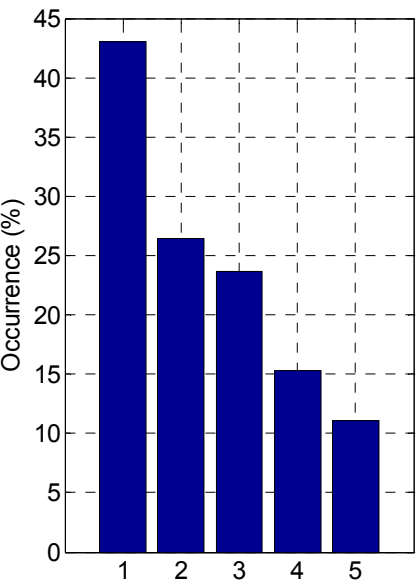

$\mathrm{Pa}_{3}$
Figure 19: Occurrence vs. parameters

\section{DISC YOUNG MODULUS}

The out of plane disc bending modes are agreed to be the generators of the air borne noise heard as squeal noise. Therefore, a study has been undertaken to assess the effect of the disc Young modulus, $E_{d}$, on predicted squeals. This study, which focuses on the forward $\mathrm{P}=\mathrm{P}_{0}$ configuration, is based on a full factorial design of experiments involving 40 values of $\mu$, from 0 to $\mu_{\max }$ and 21 values of $E_{d}$. This latter parameter, whose values have been normalized, ranges from -1.0 to 1.0 around its nominal value 0.0 . Figure 20 displays the eigenvalues computed between 0 and $4000 \mathrm{~Hz}$ corresponding to the 840 experiments. This figure highlights that the $E_{d}$ variability makes new squeal frequencies appear.

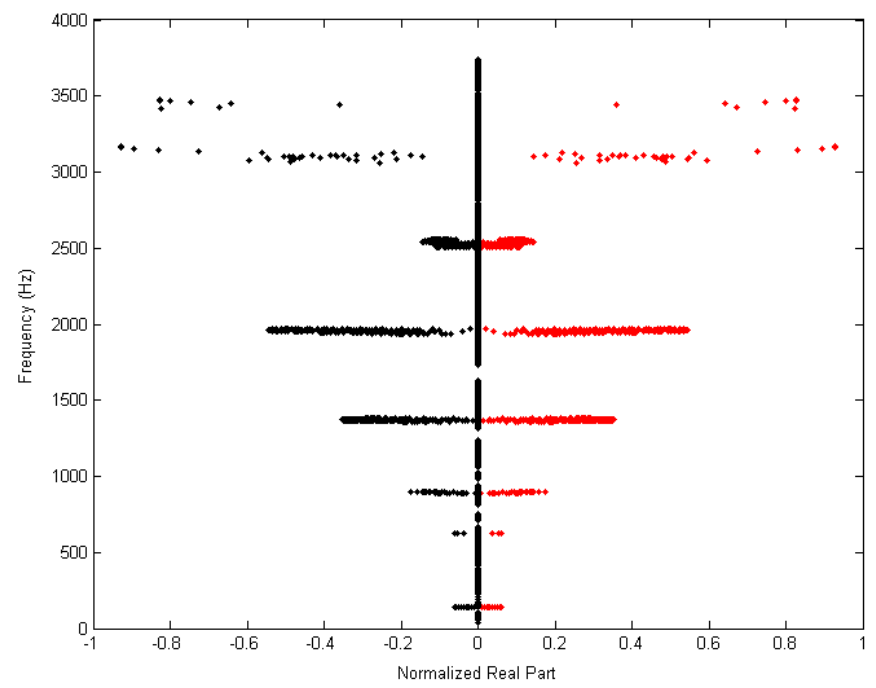

Figure 20: Complex eigenvalues - variability with $\left(\mu, E_{d}\right)$

We will now focus on the phenomena at stake around 2 $\mathrm{kHz}$ in order to depict their biparametric aspect. The corresponding frequencies and real parts are displayed with respect to both parameters $E_{d}$ and $M u$ in Figure 21 and Figure 22. The stable modes are colored in green and the unstable ones in red.

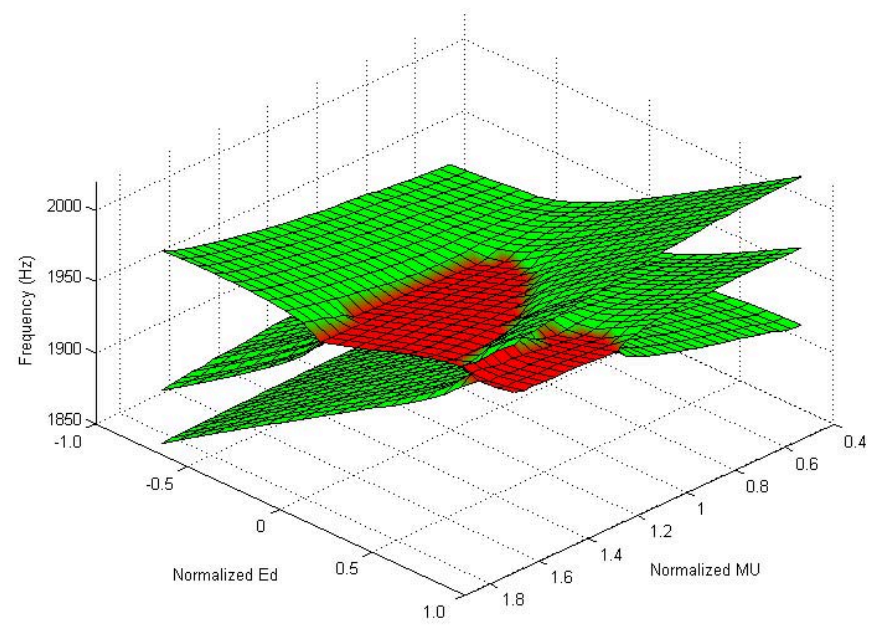

Figure 21: Biparametric evolution of the frequencies 


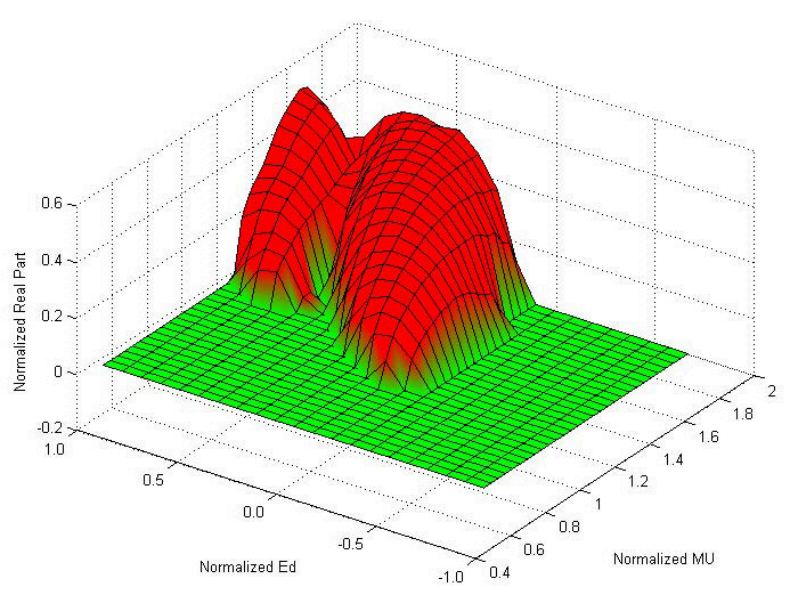

Figure 22: Biparametric evolution of the real parts

The frequency graph highlights coalescence phenomena with respect to both parameters. As explained previously, for the nominal $E_{d}$, whose normalized value is $0.0, B$ and $C$ get coupled as the friction coefficient increases. For $E_{d}=1.0$, the modes involved by the coupling are $A$ and $B$, whereas for $E_{d}=-1.0$, no coupling occurs. These coupling patterns may also be interpreted with respect to $\mathrm{Ed}$. Indeed, for $\mu=1.6, B$ and $C$ get coupled as $E_{d}$ increases. When $E_{d}$ reaches 0.8 , the two modes split and $B$ coalesces with $A$. This phenomenon may also be noticed on the real part graph as a sudden valley.

The real part data have been treated to draw the system stability charts displayed in Figure 23 and Figure 24. These charts deal with counting the number of unstable modes for each couple $(\mu, E d)$ on a given frequency range. The white areas are stable whereas the gray and black ones mean respectively one and two or more unstable modes. This kind of figures illustrates the system robustness in terms of squeal to $\mu$ and Ed. Indeed, as we can notice on the $1850-2000 \mathrm{~Hz}$ chart, the nominal working point $(1,0)$ is on the stability border. Therefore, small variations of the parameters make the system become either stable or unstable.

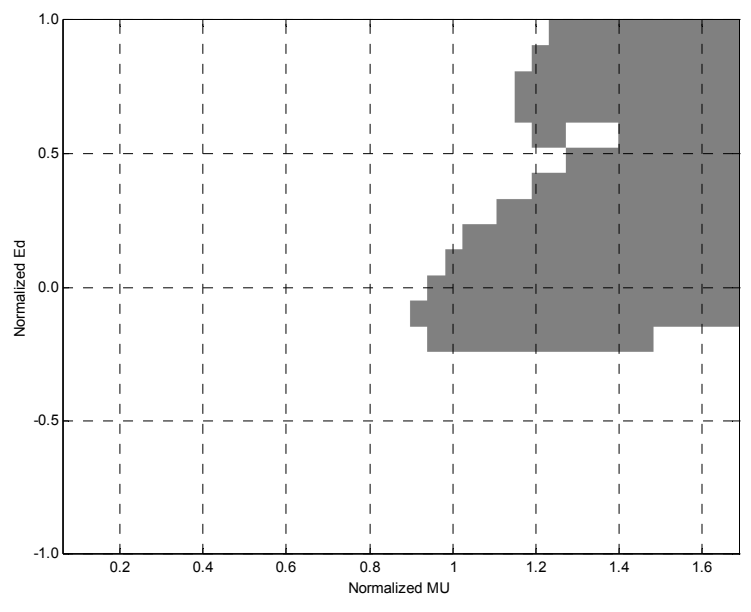

Figure 23: Stability chart - 1850-2000 Hz

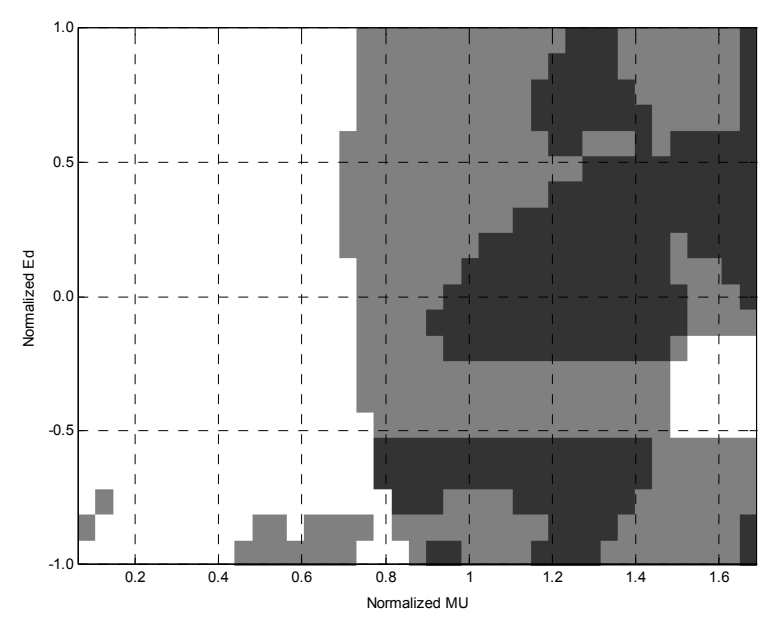

Figure 24: Stability chart $-1000-4000 \mathrm{~Hz}$

\section{CONCLUSION}

This study deals with the modeling, in terms of squeal behavior, of a commercial front brake system. A detailed FE model considering contact as surface interactions has been presented. It has been employed to compute the steady sliding position and to extract the system complex eigenvalues. Since friction is the root cause of instabilities, its effect on the static and dynamic behavior of the brake has been analyzed. An increase in this parameter turns out to skew the caliper and the anchor bracket, leading to an inhomogeneous contact pressure distribution between parts. Moreover, an increase in this parameter alters the dynamic behavior, which follows a mode coupling mechanism that has been highlighted by means of coalescence curves. Nevertheless, these coalescence curves are more complicated than the ones shown by linear models, especially for small friction values, since static position changes occur in this friction range.

Then, comprehensive parametric studies are to be done in order to investigate the fugitive nature of brake squeal. Since this is too expensive in CPU time with the detailed model, a parametric model has been built up. This model, which keeps the main features of the detailed one, has been used to undertake an accurate study with respect to the friction coefficient, both in forward and backward motion. It highlights coalescence curves altered by static position changes for low friction. The same kind of consideration is observed with respect to hydraulic pressure. In both cases, the coalescence curves are discontinuous because of static position changes occurring due to weak loading. A numerical matrix test has been conducted in order to synthesize the brake behavior in the wide variety of conditions it may encounter. Finally, a full factorial design of experiments has been conducted with respect to the friction coefficient and the disc Young modulus. This analysis highlights biparametric coupling patterns and stability charts. Both numerical matrix tests and designs of experiments are tools able to assess the stability and the robustness of the brake. 


\section{REFERENCES}

[1] G.D. Liles, "Analysis of disc brake squeal using finite element methods", SAE paper 891150

[2] A. Bajer, V. Belsky, S.W. Kung, "The Influence of Friction-Induced Damping and Nonlinear Effects on Brake Squeal Analysis", SAE paper 2004-01-2794.

[3] A. Bajer, V. Belsky, L.J. Zeng, "AutomotiveCombining a Nonlinear Static and Complex Eigenvalue Extraction in Brake Squeal Simulation", SAE paper 2003-01-3349.

[4] S.W. Kung, G. Stelzer, V. Belsky, A. Bajer, "Brake Squeal Analysis Incorporating Contact Conditions and Other Nonlinear Effetcs", SAE paper 2003-013343

[5] A.R. Abu Bakar, H. Ouyang, L. Li, J. E. Siegel, "Brake Pad Surface Topography Part I : Contact Pressure Distributions", SAE paper 2005-01-3941

[6] A.R. Abu Bakar, H. Ouyang, L. Li, J. E. Siegel, "Brake Pad Surface Topography Part II : Squeal Generation and Prevention", SAE paper 2005-013935

[7] G. Fritz, J.J. Sinou, J.M. Duffal, L. Jézéquel: "Parameter analysis of brake squeal using finite element method", European Journal of Computational Mechanics 